\title{
Identification, Isolation, and Characterization of Medipeptins, Antimicrobial Peptides From Pseudomonas mediterranea EDOX
}

\author{
Lu Zhou, Anne de Jong, Yunhai Yi and Oscar P. Kuipers* \\ Department of Molecular Genetics, University of Groningen, Groningen, Netherlands
}

OPEN ACCESS

Edited by:

Jørgen J. Leisner,

University of Copenhagen, Denmark

Reviewed by:

Eugene A. Rogozhin,

Institute of Bioorganic Chemistry, Russian Academy of Sciences (RAS),

Russia

Fabian M. Commichau,

Brandenburg University of

Technology Cottbus-Senftenberg,

Germany

*Correspondence:

Oscar P. Kuipers

o.p.kuipers@rug.nl

Specialty section:

This article was submitted to

Antimicrobials, Resistance and

Chemotherapy,

a section of the journal

Frontiers in Microbiology

Received: 29 June 2021

Accepted: 20 August 2021 Published: 14 September 2021

Citation:

Zhou L, de Jong $A, Y i Y$ and Kuipers OP (2021) Identification, Isolation, and Characterization of

Medipeptins, Antimicrobial

Peptides From Pseudomonas mediterranea EDOX.

Front. Microbiol. 12:732771. doi: 10.3389/fmicb.2021.732771
The plant microbiome is a vastly underutilized resource for identifying new genes and bioactive compounds. Here, we used Pseudomonas sp. EDOX, isolated from the leaf endosphere of a tomato plant grown on a small farm in the Netherlands. To get more insight into its biosynthetic potential, the genome of Pseudomonas sp. EDOX was sequenced and subjected to bioinformatic analyses. The genome sequencing analysis identified strain EDOX as a member of the Pseudomonas mediterranea. In silico analysis for secondary metabolites identified a total of five non-ribosomally synthesized peptides synthetase (NRPS) gene clusters, related to the biosynthesis of syringomycin, syringopeptin, anikasin, crochelin A, and fragin. Subsequently, we purified and characterized several cyclic lipopeptides (CLPS) produced by NRPS, including some of the already known ones, which have biological activity against several plant and human pathogens. Most notably, mass spectrometric analysis led to the discovery of two yet unknown CLPs, designated medipeptins, consisting of a 22 amino acid peptide moiety with varying degrees of activity against Gram-positive and Gram-negative pathogens. Furthermore, we investigated the mode of action of medipeptin A. The results show that medipeptin A acts as a bactericidal antibiotic against Gram-positive pathogens, but as a bacteriostatic antibiotic against Gram-negative pathogens. Medipeptin A exerts its potent antimicrobial activity against Gram-positive bacteria via binding to both lipoteichoic acid (LTA) and lipid II as well as by forming pores in membranes. Collectively, our study provides important insights into the biosynthesis and mode of action of these novel medipeptins from P. mediterranea EDOX.

Keywords: Pseudomonas, genome mining, biosynthesis, cyclic lipopeptides, mode of action

\section{INTRODUCTION}

Pseudomonas bacteria are found in abundance in nature and have a fascinating metabolic diversity, which is linked to their ability to colonize a diverse range of ecological niches (Gotze and Stallforth, 2020). Pseudomonas species have a wide metabolic range and can produce diverse metabolites, including cyclic lipopeptides (CLPs), 2,4-diacetylphloroglucinol (DAPG), pyrrolnitrin (PRN), pyoluteorin (PLT), phenazines (PHZs), 2,5-dialkylresorcinol, gluconic acid, quinolones, rhamnolipids, siderophores, and hydrogen cyanide. It is obvious that the bacteria 
from the genus Pseudomonas represent a rich source of natural products (Gross and Loper, 2009; D'aes et al., 2010; Masschelein et al., 2017; Zhao et al., 2019).

With the progress made by up-to-date nucleotide-sequencing techniques, a new age of natural products discovery has begun, greatly accelerated by the pace of genome sequencing of microorganisms. This advancement has paved the way for the effective prediction of gene clusters encoding new bioactive compounds and the understanding of the underlying biosynthetic processes (Vater et al., 2018). Genome mining studies of Pseudomonas species have shown a wide variation of biosynthetic gene clusters (BGCs) between genera, species, and even strains within the same species (Loper et al., 2012; Van Der Voort et al., 2015). Pseudomonas species produce non-ribosomally synthesized peptides (NRPs), which are oligopeptides (8-25 amino acids) that are N-terminally acylated with a fatty acid. This kind of bacterial natural product is formed by non-ribosomally synthesized peptide synthetases (NRPSs), which may insert non-canonical amino acids into extending peptides (Schwarzer et al., 2003; Weissman, 2015; Gotze and Stallforth, 2020). The vast majority of pseudomonal lipopeptides are not linear, but rather have a macrolactone ring shaped between the peptide's C-terminus and the hydroxyl group of a serine or threonine. The macrocycles vary in size from four to 10 amino acids (Gotze and Stallforth, 2020).

All known CLPs produced by Pseudomonas species can be classified into 14 major groups, according to the length and structure of the oligopeptide. The majority of them have antifungal and antibacterial properties, while others have antioomycete, antiviral, antiprotozoan, and antitumor properties (Geudens and Martins, 2018). CLPs inhibit bacterial growth by affecting either cell wall biosynthesis or cell membrane integrity. In brief, CLPs can insert into plasma membranes and alter their microdomain membrane fluidity. This can result in a rearrangement of plasma membrane architecture, which can cause depolarization and ion leakage or influx, both of which can cause cell death or compromised proliferation (Muller et al., 2016). In general, most CLPs from Pseudomonas species tested exhibit activity against Gram-positive bacteria in the low micromolar range, but not against Gram-negative bacteria (Raaijmakers et al., 2006; Reybroeck et al., 2014).

\section{MATERIALS AND METHODS}

\section{Isolation of Bacteria}

The isolation of bacteria from leaves was conducted according to a previous protocol (Zhou et al., 2021). In brief, $1 \mathrm{~g}$ tomato leaves was surface-sterilized for $1 \mathrm{~min}$. in $70 \%$ ethanol and $3 \mathrm{~min}$. in $0.5 \% \mathrm{NAClO}$ solution combined with one droplet Tween 80 per $100 \mathrm{ml}$ solution. After that, leaves were rinsed 5 times in sterilized deionized water. Subsequently, the leaves were macerated in $9 \mathrm{ml}$ of $10 \mathrm{mM} \mathrm{MgSO}_{4}$ buffer with a mortar to get the tissue suspension. After dilution $10^{3}-10^{6}$ times with $10 \mathrm{mM} \mathrm{MgSO}_{4}$ buffer, the suspension was spread on lysogeny broth (LB) agar plates. To obtain single colonies, the plates were incubated at $28^{\circ} \mathrm{C}$ for $24-48 \mathrm{~h}$. Surface sterilization was validated by spreading aliquots of the final rinsing by deionized water on LB agar plates (if no organism growth was detected after 7 days, surface sterilization was deemed successful).

\section{Whole Genome Sequencing and Assembly}

Genomic DNA was extracted from a culture grown from a single colony using a GenElute bacterial genomic DNA kit (Sigma) according to the manufacturer's instructions. The genomes were sequenced at GATC Biotech (Germany) using an Illumina HiSeq sequencing system. Raw reads were validated by FastQC version 0.11.5 (Andrews, 2010). Trimmomatic version 0.38 was used to delete low-quality reads (Bolger et al., 2014). Subsequently, the reads were assembled de novo using SPAdes version 3.11.1 (Bankevich et al., 2012). Default parameters were used for all software unless specified. The draft genomes were then annotated by the Rapid Annotations using Subsystems Technology (RAST) server. The $\mathrm{dDDH}$ and ANI values were determined using the online applications TYGS (Meier-Kolthoff and Goker, 2019) and JSpeciesWS (Richter et al., 2016), respectively, for the categorization of species affiliations.

\section{Genome Mining of Biosynthetic Gene Clusters}

In order to identify biosynthesis gene clusters (BGCs) in strain EDOX, the draft genome sequence was constructed into a pseudomolecule using the Medusa web server ${ }^{1}$ (Bosi et al., 2015) with multiple closely related strains as references. The pseudomolecules were then sent to antiSMASH 5.0 (Blin et al., 2019) and BAGEL 4 (van Heel et al., 2018) for BGC mining.

\section{Purification of Antimicrobial Compounds From the EDOX Strain}

For antimicrobial compounds purification, seed culture of strain EDOX was cultivated in $4 \mathrm{ml}$ King's $\mathrm{B}(\mathrm{KB})$ media contained in a glass tube and shaken on a rotary shaker for $24 \mathrm{~h}$ at $28^{\circ} \mathrm{C}, 210 \mathrm{rpm}$. Subsequently, the seed culture was inoculated in 2-L flasks containing $400 \mathrm{ml} \mathrm{KB}$ media at $210 \mathrm{rpm}$ for $48 \mathrm{~h}$. The supernatant was collected by centrifugation $(10,000 \times g$, $30 \mathrm{~min}$ ) and acidified to $\mathrm{pH} 2$ with $6 \mathrm{~N}$ hydrochloric acid $(\mathrm{HCl})$ and kept overnight at $4^{\circ} \mathrm{C}$ for precipitation of CLPs. After that, the precipitates were collected by centrifugation $(10,000 \times g, 30 \mathrm{~min})$ and extracted using methanol. To get crude CLPs extracts, methanol was evaporated at room temperature. The crude extracts were dissolved in Milli-Q water and filtered with $0.45 \mu \mathrm{m}$ Durapore ${ }^{\mathrm{TM}}$ membrane and then subjected to a reverse high-performance liquid chromatography (HPLC) equipped with Aeris widepore $3.6 \mu \mathrm{XB}-\mathrm{C} 18250 \times 4.6 \mathrm{~mm}$ column for purification. The mobile phases were HPLC-grade water supplemented with $0.1 \%$ trifluoroacetic acid (TFA; solvent A) and acetonitrile supplemented with $0.1 \%$ TFA (solvent B). An elution gradient of solvent A/solvent B (75:25 to 0:100) was applied at a flow rate of $1 \mathrm{ml} / \mathrm{min}$, for compound purification. A UV detector set at a wavelength of $214 \mathrm{~nm}$ was used to monitor the compound's elution.

${ }^{1}$ http://combo.dbe.unifi.it/medusa 


\section{Liquid Chromatography-Tandem Mass Spectrometry Analysis}

A Q-Exactive Orbitrap ${ }^{\mathrm{TM}}$-based mass spectrometer equipped with an Ultimate 3000 UPLC, an ACQUITY BEH C18 column (2.1 $50 \mathrm{~mm}, 1.7 \mathrm{~m}$ particle scale, 200; Waters), a HESI-II ion source, and an Orbitrap detector was used to perform LC-MS/MS to obtain insight into the molecular configurations of the peptides. In each run, a 30-min gradient of $5-90 \% \mathrm{MeCN} /$ Milli-Q water (v/v) with $0.1 \%$ formic acid (v/v) was used with a flow rate of $0.35 \mathrm{ml} / \mathrm{min}$. The doubly and triply charged ions of the compound of interest were selected by MS/MS in a separate run in PRM mode.

\section{Determination of the Minimum Inhibitory Concentration}

MIC tests were conducted in triplicate using liquid growth inhibition microdilution assays in sterile polypropylene microtiter plates according to the Clinical and Laboratory Standards Institute (CLSI) guideline (Wiegand et al., 2008; Hindler and Richter, 2016). The pathogenic indicator strains were streaked on LB agar plates first, and then, single colonies were selected and incubated in LB broth overnight. The final bacteria inoculum was prepared in CAMHB (cationic adjusted Mueller-Hinton broth, Sigma-Aldrich) at $5 \times 10^{5} \mathrm{CFU} / \mathrm{ml}$. The antimicrobials were serially diluted two times, and $50 \mu$ l of diluted bacterial suspension was applied to each well to make the final volume $100 \mu$ l. Without stirring, the microtiter plates were incubated for $48 \mathrm{~h}$ at $30^{\circ} \mathrm{C}$. The $\mathrm{OD}_{600}$ was measured using a microplate reader (Tecan Infinity F200) to determine growth inhibition. The MIC value is described as the lowest concentration of antimicrobials that inhibits a pathogen's visible growth.

\section{Time-Kill Assay}

This assay was performed according to a previously described protocol with small modification (Ling et al., 2015). An overnight culture of either Staphylococcus aureus 533R4 or X. translucens pv. graminis LMG587 was diluted 50-fold in MHB and incubated at $30^{\circ} \mathrm{C}$ with the shaker at $220 \mathrm{rpm}$. Bacteria were grown to an $\mathrm{OD}_{600}$ of 0.5 , and then, the concentration of cells was adjusted to $\approx 5 \times 10^{5}$ cells per $\mathrm{ml}$ for $X$. translucens and $\approx 2 \times 10^{8}$ for S. aureus. Bacterial cultures were then exposed to $10 \mathrm{X}$ MIC antimicrobials at $30^{\circ} \mathrm{C}$ and $220 \mathrm{rpm}$. Bacteria not treated with medipeptin A were used as a negative control. Bacteria treated with vancomycin or colistin were used as a positive control. At desired time points $(0,1,2,3,4,5$, and $6 \mathrm{~h}), 10 \mu \mathrm{l}$ culture was taken and tenfold serially diluted. Subsequently, each sample was plated on MHA plates. After incubation at $30^{\circ} \mathrm{C}$ for $48 \mathrm{~h}$, colonies were counted and the number of $\mathrm{CFU}$ per $\mathrm{ml}$ was calculated. Each experiment was performed in triplicate.

\section{Membrane Permeabilization Assays}

In order to investigate whether medipeptin A could permeabilize the cell membranes, a commercial LIVE/DEAD Baclight Bacterial Viability Kit (Invitrogen) was used. Cells of $S$. aureus were grown in $\mathrm{LB}$ overnight and diluted to an $\mathrm{OD}_{600}$ of 0.2 . Compound medipeptin A was added at a concentration of $40 \mu \mathrm{g} / \mathrm{ml}$ (5X MIC) in $1 \mathrm{ml}$ culture, while nisin was added at a concentration of $2.5 \mu \mathrm{g} / \mathrm{ml}$. The same amount of DMSO was added to the control. Cells were treated at room temperature for $1 \mathrm{~h}$ before harvest. The harvested cells were washed and resuspended in a $200 \mu \mathrm{l}$ $0.85 \%$ saline $(\mathrm{NaCl})$ solution. Two different dyes $(3.34 \mathrm{mM}$ $\mathrm{SYTO}^{\circledR} 9$ and $20 \mathrm{mM}$ propidium iodide) were added at a ratio of $1: 1(\mathrm{v} / \mathrm{v})$. Cells were stained in the dark for $30 \mathrm{~min}$, and a $2 \mu \mathrm{l}$ sample was mounted on a $1 \%$ agarose pad before being imaged using a DeltaVision Elite microscope.

\section{Lipoteichoic Acid Binding Assay}

Cultures of $S$. aureus grown overnight were diluted to an $\mathrm{OD}_{600}$ of 0.05 in a 96-well plate and incubated in a microplate spectrophotometer $\left(1,000 \mathrm{rpm}\right.$ at $\left.30^{\circ} \mathrm{C}\right)$. When the $\mathrm{OD}_{600}$ reached 0.1 , medipeptin A (dissolved in DMSO) was added to each well at a final concentration of $24 \mu \mathrm{g} / \mathrm{ml}$ (3X MIC), and the same volume of DMSO was used as a negative control. Nisin (at a final concentration of $2 \mu \mathrm{g} / \mathrm{ml}$ ) was used as a positive control for $S$. aureus. Lipoteichoic acid (LTA; at a final concentration of $100 \mu \mathrm{g} / \mathrm{ml}$ ) was added to look into the binding activity of medipeptin A. The growth curve was recorded using the microplate spectrophotometer under the same circumstances for the next $16 \mathrm{~h}$, with four replicates for each treatment. LTA is negatively charged and is thought to influence Gram-positive bacteria's sensitivity to cationic antimicrobial peptides like defensin and nisin via electrostatic contact (Yang et al., 2017). The LTA added in each sample could compete with LTA on cell envelopes for binding with cationic antimicrobial peptides, which could cause the reduction in antimicrobial activity of peptides. Comparing with only peptides treatment, medipeptin A binding to LTA is indicated by the restoration of cell growth under treatment of LTA and peptides together.

\section{Lipid II Binding Assay}

An overnight culture of $S$. aureus was mixed with precooled $\mathrm{LB}$ agar (around $55^{\circ} \mathrm{C}$ ) at a final concentration of $0.1 \%(\mathrm{v} / \mathrm{v})$, and then, the mixed media was poured onto Petri dishes to obtain pathogen-fusion agar plates. Binding of medipeptin A and lipid II was further evaluated by spotting of purified lipid II $(300 \mu \mathrm{M}, 4 \mu \mathrm{l})$ to the edge of the halo caused by each compound. Briefly, medipeptin A or vancomycin was exposed to $100^{\circ} \mathrm{C}$ for $30 \mathrm{~min}$. Then, medipeptin A or vancomycin (with or without heat treatment) was loaded to the agar plate, and after the solution drops had dried, purified lipid II was spotted to the edge (identified by a pre-experiment) of the inhibition halo formed by antibiotics. After the lipid II solution drops had dried, the plates were transferred to a $30^{\circ} \mathrm{C}$ incubator for overnight incubation. The decrease in halo size indicates the binding of lipid II and medipeptin A.

\section{RESULTS}

\section{Isolation and Identification of Strain EDOX}

The strain Pseudomonas sp. EDOX, isolated from the healthy tomato leave endosphere, showed antagonistic activity against 
both bacterial and fungal pathogens in our preliminary research. The genomic DNA was isolated and sequenced. The draft genome consists of a 6,142,102 bp. A total of 5,335 CDSs and 66 RNA genes including rRNA, tRNA, and ncRNA genes were identified. The general features of the genome of strain EDOX are summarized in Table 1. To classify at the species level, $\mathrm{ANI}$ and $\mathrm{dDDH}$ values were determined. Strain EDOX exhibited $\geq 99.27 \%$ ANI and $\geq 96.80 \% \mathrm{dDDH}$ compared with the closest related species, that is, Pseudomonas mediterranea CFBP 5447, which is above the gold standard threshold value of 95\% ANI and $70 \% \mathrm{dDDH}$ for the delineation of species. Therefore, strain EDOX was identified as Pseudomonas mediterranea EDOX. This whole genome analysis result has been deposited at DDBJ/ ENA/GenBank under the accession number GCA_016735085.1.

\section{Automated Searching for Secondary Metabolite Clusters Using the antiSMASH Pipeline}

By bioinformatic evaluation of the genome sequence of EDOX using antiSMASH 6.0, 12 biosynthetic gene clusters were identified (Table 2). Five of these are NRPs BGCs predicted to be related to the biosynthesis of syringomycin (Scholz-Schroeder et al., 2003), syringopeptin (Scholz-Schroeder et al., 2001), anikasin (Götze et al., 2017), crochelin A (Baars et al., 2018), and fragin (Jenul et al., 2018). Two were identified as type I PKs-NRPs hybrid BGCs and related to the biosynthesis of lankacidin C (Mochizuki et al., 2003) and entolysin (Vallet-Gely et al., 2010). One siderophore BGC and One Ripp-like BGC were also found in the genome. In addition, four other BGCs were discovered. Type "other BGC" is a cluster containing a secondary metaboliterelated protein that does not fit into any other category.

\section{Purification and Identification of Lipopeptides}

Two compounds, initially named edox-1 and edox-2, were isolated and purified from strain EDOX (Table 2). The compounds were subjected to LC-MS and LC-MS/MS, which showed $\mathrm{m} / \mathrm{z}$ values of $1041.60[\mathrm{M}+2 \mathrm{H}]^{2+}$ (Figure 1B) and $1026.09[\mathrm{M}+2 \mathrm{H}]^{2+}$ (Figure 1C), respectively. As shown in Figure 1, these two lipopeptides were identified as 22 amino acid cyclic lipopeptides, that is, Dhb-Pro-Ala-Ala-Ala-Val-Val-Dhb-Thr-Val-Ile-Dha-GlyAla-Ala-Val-Dhb-Thr-Ala-Dab-Ser-Ile and Dhb-Pro-Ala-AlaAla-Val-Val-Dhb-Gly-Val-Ile-Dha-Ala-Ala-Ala-Val-Dhb-Thr-AlaDab-Ser-Ile, respectively. Analyses using high-resolution LC-MS/ MS, the primary ions at $\mathrm{m} / \mathrm{z} 2082.20[\mathrm{M}+\mathrm{H}]^{+}$and 2051.18 $[\mathrm{M}+\mathrm{H}]^{+}$showed a distinct sequence tag for 16 amino acid residues with the sequences Pro-Ala-Ala-Ala-Val-Val-Dhb-ThrVal-Ile-Dha-Gly-Ala-Ala-Val-Dhb and Dhb-Pro-Ala-Ala-AlaVal-Val-Dhb-Gly-Val-Ile-Dha-Ala-Ala-Ala-Val-Dhb, respectively. Furthermore, the mass spectrum showed two larger fragments of $\mathrm{m} / \mathrm{z} 254.167$ and $\mathrm{m} / \mathrm{z}$ 473.264. The $\mathrm{m} / \mathrm{z} 254.167$ fragment's molecular formula corresponded to a Dhb residue linked to 3-OH decanoic acid also known as monomer $\mathrm{C} 10: 0-\mathrm{OH}(3)$, which is similar to the structure of corpeptin (Emanuele et al., 1998). The $\mathrm{m} / \mathrm{z} 473.264$ fragment's molecular formula has a Thr-Ala-Dab-Ser-Ile cyclic tail, which was consistent with
TABLE 1 | Draft genome features of $P$. mediterranea EDOX.

\begin{tabular}{lc}
\hline Characteristics & Genome \\
\hline Size (bp) & $6,142,102$ \\
G+C content (\%) & 61.4 \\
N50 (bp) & 422,748 \\
Genes number & 5,401 \\
Contigs & 83 \\
CDS number & 5,335 \\
rRNA & 4 \\
tRNA & 58 \\
ncRNA & 4 \\
\hline
\end{tabular}

TABLE 2 | Secondary metabolite and antibiotic gene clusters identified from P. mediterranea EDOX using antiSMASH 6.0 and BAGEL4.

\begin{tabular}{|c|c|c|c|c|}
\hline $\begin{array}{l}\text { BGCs } \\
\text { cluster }\end{array}$ & Type & $\begin{array}{l}\text { Most similar known } \\
\text { BGCs }\end{array}$ & $\begin{array}{l}\text { MIBiG BGC } \\
\text { ID }\end{array}$ & $\begin{array}{l}\text { Mass } \\
\text { spectrometry } \\
\text { Identification } \\
\text { (supernatant } \\
\text { of EDOX) }\end{array}$ \\
\hline 1 & $\begin{array}{l}\text { Type I PKs- } \\
\text { NRPs hybrid }\end{array}$ & $\begin{array}{l}\text { Lankacidin C (13\% of } \\
\text { genes show similarity) }\end{array}$ & BGC0001100 & not detected \\
\hline 2 & NRPs & $\begin{array}{l}\text { Syringomycin (100\% } \\
\text { of genes show } \\
\text { similarity) }\end{array}$ & BGC0000437 & $\begin{array}{l}\text { Cormycins } \\
\text { (Strano et al., } \\
\text { 2015) }\end{array}$ \\
\hline 3 & NRPs & $\begin{array}{l}\text { Syringopeptin (100\% } \\
\text { of genes show } \\
\text { similarity) }\end{array}$ & BGC0000438 & $\begin{array}{l}\text { edox-1, } \\
\text { edox-2* }\end{array}$ \\
\hline 4 & Siderophore & - & - & not detected \\
\hline 5 & NRPs & $\begin{array}{l}\text { Anikasin ( } 22 \% \text { of } \\
\text { genes show similarity) }\end{array}$ & BGC0001509 & not detected \\
\hline 6 & $\begin{array}{l}\text { Type I PKs- } \\
\text { NRPs hybrid }\end{array}$ & $\begin{array}{l}\text { Entolysin ( } 17 \% \text { of } \\
\text { genes show similarity) }\end{array}$ & BGC0000344 & not detected \\
\hline 7 & NRPs & $\begin{array}{l}\text { Crochelin A ( } 15 \% \text { of } \\
\text { genes show similarity) }\end{array}$ & BGC0002001 & not detected \\
\hline 8 & Other & $\begin{array}{l}\text { Fengycin ( } 13 \% \text { of } \\
\text { genes show similarity) }\end{array}$ & BGC0001095 & not detected \\
\hline 9 & Other & - & - & not detected \\
\hline 10 & RiPP & - & - & not detected \\
\hline 11 & Other & $\begin{array}{l}\text { APE Vf ( } 45 \% \text { of } \\
\text { genes show similarity) }\end{array}$ & BGC0000837 & not detected \\
\hline 12 & NRPs & $\begin{array}{l}\text { Fragin ( } 37 \% \text { of genes } \\
\text { show similarity) }\end{array}$ & BGC0001599 & not detected \\
\hline
\end{tabular}

Hyphens (-) were indicating that no similarity was found with known biosynthetic gene clusters (BGCs) in MIBiG repository.

*edox-1 and edox-2 were later renamed as medipeptin $A$ and medipeptin $B$.

nunapeptin (Michelsen et al., 2015; Hennessy et al., 2017) and corpeptin. Lipopeptides edox-1 and edox-2 showed some structural resemblance to nunapeptin from $P$. fluorescens In5 (Michelsen et al., 2015), to braspeptin from Pseudomonas sp. $11 \mathrm{~K} 1$ (Zhao et al., 2019), and to corpeptin A from P. corrugate CFBP 5454 (Emanuele et al., 1998; Strano et al., 2015) as well as to thanapeptin from Pseudomonas sp. SH-C52 (Van Der Voort et al., 2015; Figure 2). Therefore, in agreement with the naming of corpeptin produced by $P$. corrugate, we designated the edox- 1 and edox- 2 as medipeptin $\mathrm{A}$ and medipeptin B, respectively. Based on the genome mining data, these two lipopeptides purified from the bacteria culture are obviously in accordance with cluster 3 identified by antiSMASH 6.0 (Figure 3). 


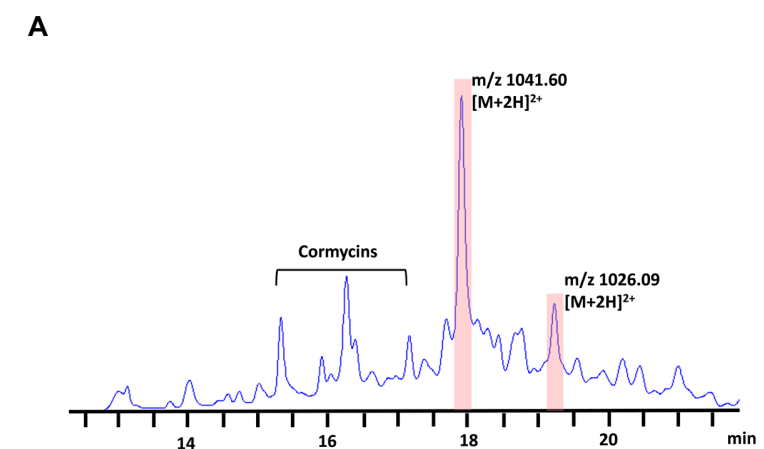

C
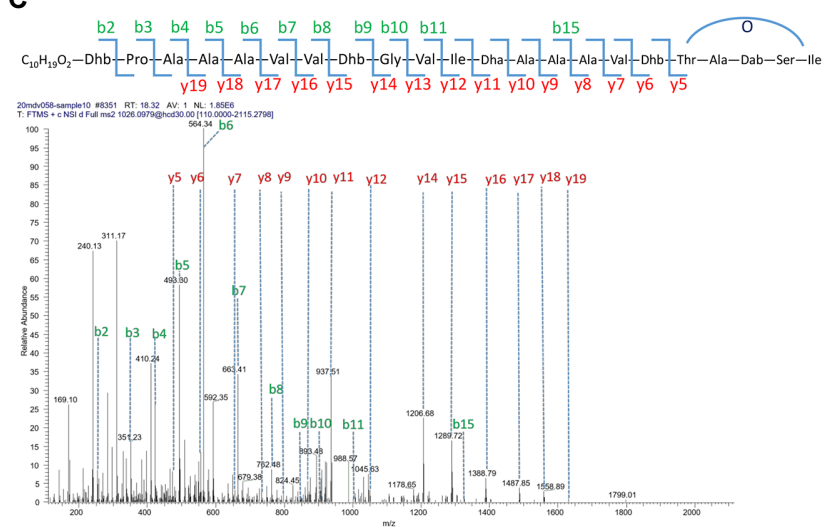

B

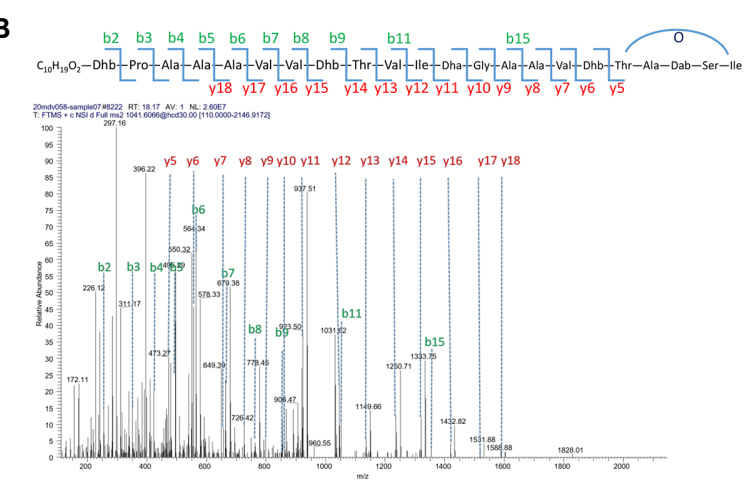

D

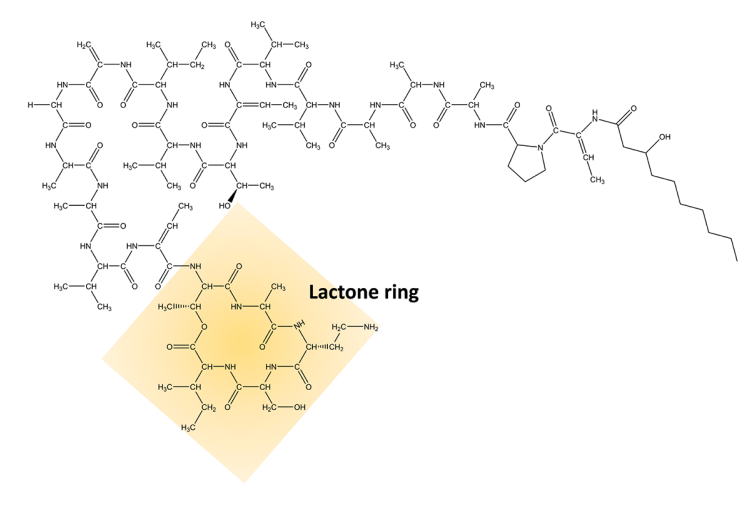

FIGURE 1 | Characterization of Purified CLPs produced by strain EDOX. (A) HPLC chromatographic profile of crude extract from supernatant of strain EDOX. (B) De novo sequencing of medipeptin A ( $\mathrm{m} / \mathrm{z}$ 2082.20) predicted from gene cluster 3 obtained by genome mining of $P$. mediterranea EDX by using LC-MS/MS. (C) De novo sequencing of the medipeptin B ( $\mathrm{m} / \mathrm{z}$ 2051.18) encoded by gene cluster 3 by using LC-MS/MS. (D) The proposed chemical structure of medipeptin A.

\begin{tabular}{|c|c|c|c|c|c|c|c|c|c|c|c|c|c|c|c|c|c|c|c|c|c|c|c|}
\hline medipeptin A & $2082.22\left[\mathrm{M}+\mathrm{H}^{+}\right]$ & $\mathrm{C}_{10} \mathrm{H}_{19} \mathrm{O}_{2}$ & Dhb & Pro & Ala & Ala & Ala & Val & Val & Dhb & Thr & Val & Ile & Dha & Gly & Ala & Ala & Val & Dhb & Thr Ala & Dab & Ser & Ile \\
\hline medipeptin B & $2051.20\left[\mathrm{M}+\mathrm{H}^{+}\right]$ & $\mathrm{C}_{10} \mathrm{H}_{19} \mathrm{O}_{2}$ & Dhb & Pro & Ala & Ala & Ala & Val & Val & Dhb & Gly & Val & lle & Dha & Ala & Ala & Ala & Val & Dhb & Thr Ala & Dab & Ser & Ile \\
\hline corpeptin & $2095.21\left[\mathrm{M}+\mathrm{H}^{+}\right]$ & $\mathrm{C}_{10} \mathrm{H}_{19} \mathrm{O}_{2}$ & Dhb & Pro & Ala & Ala & Ala & Val & Val & Dhb & Hse & Val & Ile & Dha & Ala & Ala & Ala & Val & Dhb & Thr Ala & Dab & Ser & Ile \\
\hline nunapeptin & $2109.22\left[\mathrm{M}+\mathrm{H}^{+}\right]$ & $\mathrm{C}_{12} \mathrm{H}_{23} \mathrm{O}_{2}$ & Dhb & Pro & Ala & Ala & Ala & Val & Ala & Dhb & Ser & Val & $\|$ ll & Dha & Ala & Val & Ala & Val & Dhb & Thr Ala & Dab & Ser & Ile \\
\hline thanapeptin & $2120.22\left[\mathrm{M}+\mathrm{H}^{+}\right]$ & $\mathrm{C}_{10} \mathrm{H}_{19} \mathrm{O}_{2}$ & Dhb & Pro & Ala & Ala & Pro & Val & Val & Dhb & Thr & Val & lle & Dha & Ala & Ala & Ala & Val & Dhb & Thr Ala & $\mathrm{Dab}$ & Ser & Ile \\
\hline syringopeptin & $2144.20\left[\mathrm{M}+\mathrm{H}^{+}\right]$ & $\mathrm{C}_{10} \mathrm{H}_{19} \mathrm{O}_{2}$ & Dhb & Pro & Val & Val & Ala & Ala & Val & Val & Dhb & Ala & Val & Ala & Ala & Dhb & Thr & Ser & Ala & Dhb Ala & Dab & Dab & Tyr \\
\hline
\end{tabular}

FIGURE 2 | Comparison of medipeptins with similar CLPs. The macrolactone ring shaped between the C-terminus of each peptide and a hydroxyl group of a threonine is remarked by square area. The different parts in medipeptins, compared with other CLPs, were marked in red. Non-canonical amino acids are abbreviated as follows: Dhb, dehydrobutyrine; Hse, homoserine; Dha, dehydroalanine; and Dab, 2,4-diaminobutyric acid.

\section{Biosynthesis of Medipeptins by Pseudomonas sp. EDOX}

Based on the genome mining, a total of 12 BGCs were discovered in the genome of strain EDOX. We identified and characterized the gene cluster for medipeptin biosynthesis (Figure 3).
This BGC contains 11 genes, including three large biosynthetic genes $(m e p A-C)$, six genes associated with export of peptides ( $m e p D, p s e A-C, p s e E$, and $p s e F$ ), one gene related to biosynthesis regulation of medipeptins $(m e p P)$, and one gene encoding a thioesterase (TE) domain. Based on the structure of medipeptins, 


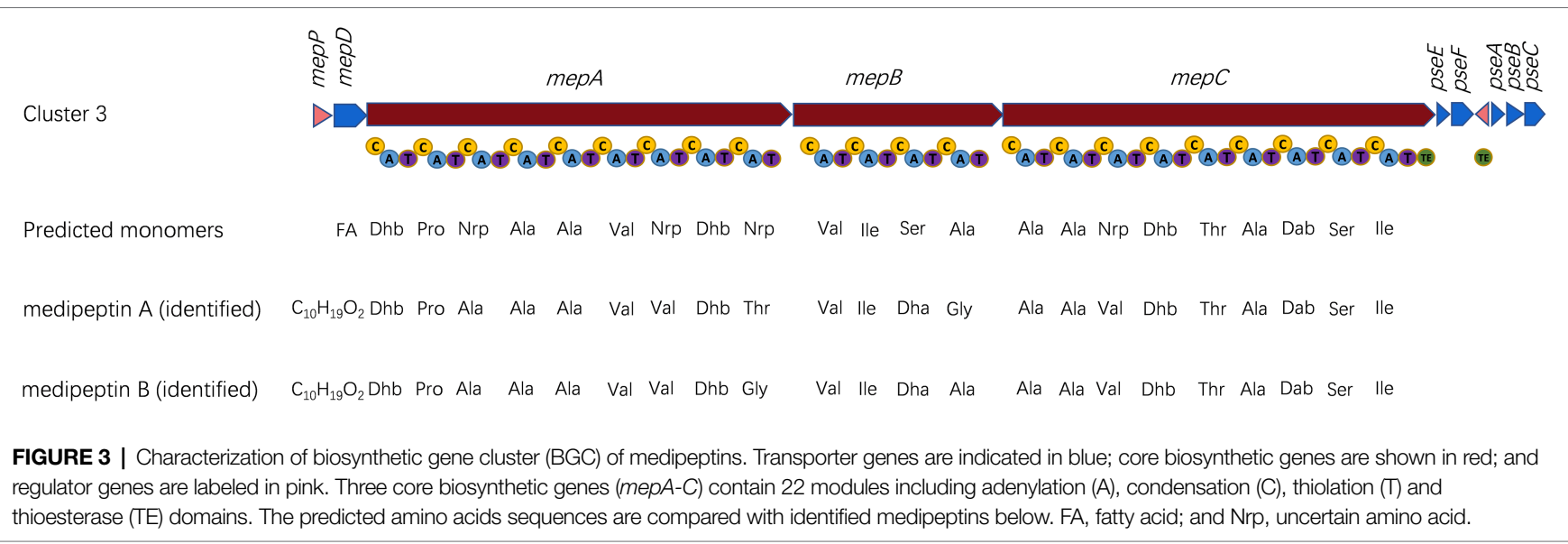

we determined that medipeptin biosynthesis is catalyzed by genes mepA-C in a colinear manner, which is identical to the biosynthesis of corpeptin (Strano et al., 2015). Moreover, medipeptin A and B show two amino acid residues difference in corpeptin and nunapeptin, one amino acid residue difference in thanapeptin, and 16 amino acids residues difference in syringopeptin (Figure 2). All these differences may lead to distinctive antimicrobial activity of each lipopeptide.

\section{Determination of MIC}

The antimicrobial activity of medipeptin A against pathogenic bacteria was determined by MIC assays. In our study, purified medipeptin A showed potent antimicrobial activity against several tested Gram-negative pathogens, including X. translucens, P. syringae, and $X$. campestris, with a MIC value of $4-16 \mu \mathrm{g} / \mathrm{ml}$ (Table 3). In addition, purified medipeptin A also showed potent antimicrobial activity against Gram-positive bacteria, including M. flavus, S. aureus, and $B$. cereus, with a MIC value of $2-8 \mu \mathrm{g} / \mathrm{ml}$ (Table 3).

\section{Medipeptin A Acts as a Bactericidal Antibiotic Against Gram-Positive Pathogens but as a Bacteriostatic Antibiotic Against Gram-Negative Pathogens}

The time dependency of antibiotic action is a sound method for determining whether a compound is bacteriostatic or bactericidal. In this study, we monitored the killing kinetics of medipeptin A against X. translucens and S. aureus. Lipopeptide medipeptin A showed bactericidal capacity against S. aureus, and it killed all the $S$. aureus in $4 \mathrm{~h}$ at a desirable concentration (10X MIC; Figure 4A). However, the growth of X. translucens cells treated with medipeptin A just stopped or showed limited growth when compared to the untreated cells (Figure 4A). These results demonstrate that medipeptin A may act as a bactericidal antibiotic against $S$. aureus and acts as a bacteriostic antibiotic against $X$. translucens.

\section{Medipeptin A Permeabilizes the Cell Membrane of Gram-Positive Bacteria}

We analyzed whether medipeptin A can permeabilize the cell membrane of $S$. aureus using a commercial LIVE/DEAD Baclight
Bacterial Viability Kit (Invitrogen). Cells with an intact membrane will stain green, whereas cells with a compromised membrane will stain red. The results show that medipeptin A disrupts the membrane of $S$. aureus cells when compared to the control treated with DMSO, which showed no influence on the membrane permeability of $S$. aureus cells (Figure 4B). These results demonstrate that medipeptin $\mathrm{A}$ acts as a potent antibiotic against Gram-positive bacteria by disrupting the cytoplasmic membrane.

\section{Medipeptin A Binds to Lipoteichoic Acid and Lipid II}

To assess whether medipeptin A has LTA binding action, bacterial growth assays were performed in 96-well plate with or without LTA. The results showed that cells treated with medipeptin $\mathrm{A}$ at a concentration of $3 \mathrm{X}$ MIC value grew and untreated cells when both of them were exposed to LTA (Figure 4C), which demonstrates that medipeptin A has an LTA binding capacity. Furthermore, the addition of lipid II originating from Gram-positive bacteria (lipid II-Lys) decreased the inhibition zone of medipeptin A toward $S$. aureus (Figure 4D), suggesting that medipeptin A binds to Grampositive-type lipid II as well. Moreover, medipeptin A still showed similar inhibition zone of $S$. aureus before and after heat treatment $\left(100^{\circ} \mathrm{C}, 30 \mathrm{~min}\right)$, suggesting that the activity of medipeptin $\mathrm{A}$ is heat-stable.

\section{DISCUSSION}

In this study, we isolated and characterized Pseudomonas mediterranea EDOX from healthy tomato leaf endosphere. This strain can produce medipeptins to exert strong inhibitory activity against plant and human pathogens. In addition, we sequenced the genome of strain EDOX and conducted in silico analysis of BGCs. Furthermore, two CLPs, designated as medipeptins, were purified and characterized and their encoding gene cluster was identified. Their predicted sequence is shown in Figure 3. Subsequently, we investigated the mechanisms of medipeptins against Gram-positive and Gram-negative pathogens. 
TABLE 3 | MIC value of medipeptin A against pathogenic bacteria.

\begin{tabular}{|c|c|c|c|c|}
\hline \multirow{2}{*}{ Type of pathogens } & \multirow{2}{*}{ Pathogens } & \multicolumn{3}{|c|}{ MIC ( $\mu \mathrm{g} / \mathrm{ml})$} \\
\hline & & medipeptin A & Colistin & Vancomycin \\
\hline \multirow[t]{7}{*}{ Gram-negative } & Xanthomonas campestris pv. campestris NCCB92058 & 16 & 1 & nd \\
\hline & Xanthomonas translucens pv. graminis LMG587 & 4 & 1 & nd \\
\hline & Pseudomonas syringae pv. tomato DC3000 & 8 & 1 & nd \\
\hline & Ralstonia syzygii subsp. Syzygii LMG6969 & $>32$ & 1 & nd \\
\hline & Escherichia coli ET8 & $>32$ & 2 & nd \\
\hline & Klebsiella pneumoniae LMG20218 & $>32$ & 2 & nd \\
\hline & Acinetobacter baumannii LMG01041 & $>32$ & 2 & nd \\
\hline \multirow[t]{3}{*}{ Gram-positive } & Staphylococcus aureus subsp. aureus 5334R4 & 8 & nd & 0.5 \\
\hline & Bacillus cereus ATCC14579 & 8 & nd & 0.5 \\
\hline & Micrococcus flavus (not pathogenic) & 2 & nd & 0.25 \\
\hline
\end{tabular}

nd was indicating that MIC values were not detected.

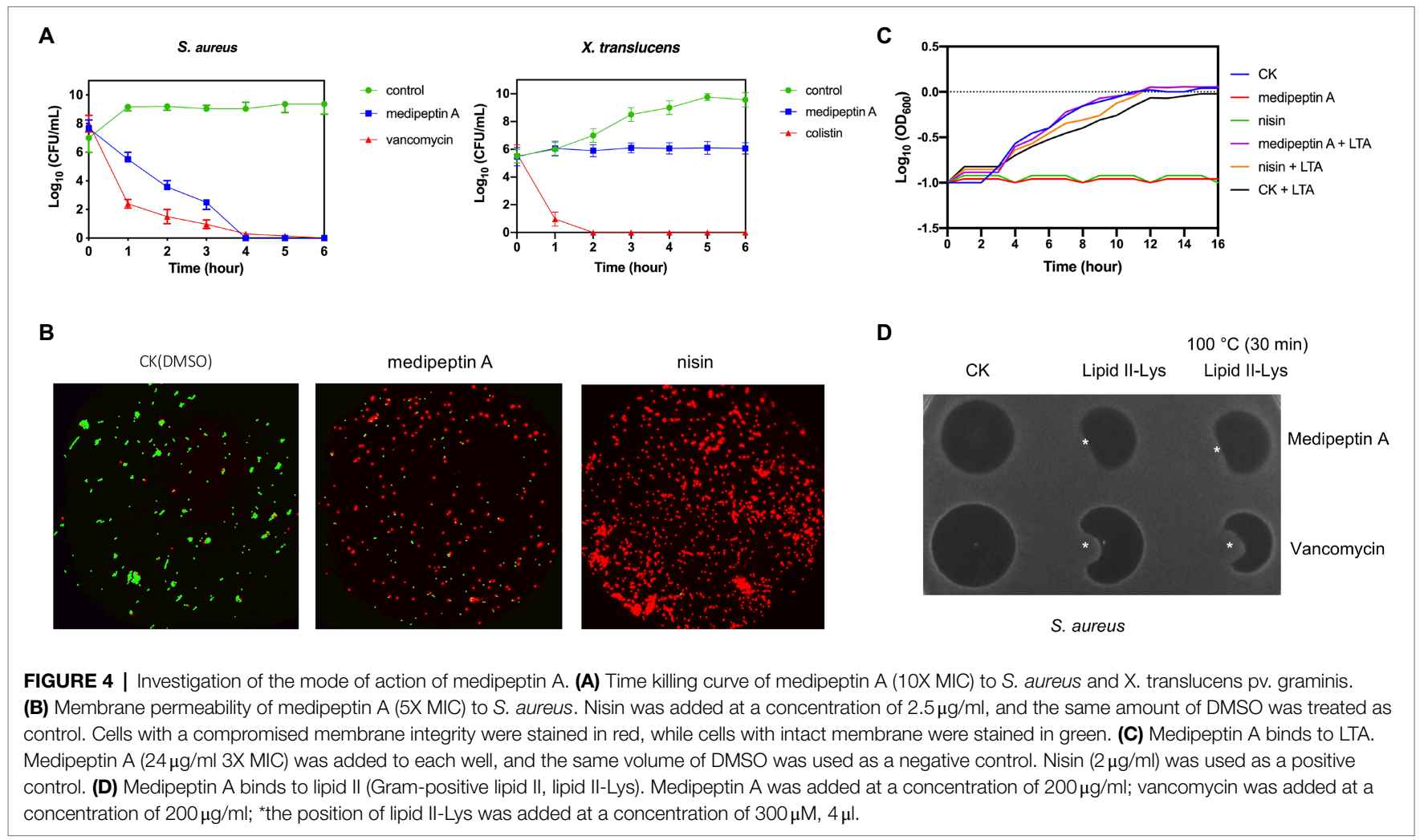

Medipeptin A, binding to both LTA and lipid II as well as forming pores in membranes, is bacteriocidal against Grampositive bacteria (Staphylococcus aureus subsp. aureus 5334R4). In contrast, medipeptin $\mathrm{A}$ acts as a bacteriostatic antibiotic against Gram-negative pathogens (Xanthomonas translucens pv. graminis LMG587). These findings are suggesting that medipeptins have potential to make contribute to develop new antibiotics and provide alternatives treatments for pathogens. Interestingly, $P$. mediterranea is a pathogenic species for plants such as P. mediterranea CFBP 10906 (Alippi and López, 2010). However, our strain P. mediterranea EDOX was isolated from leave endosphere of a healthy tomato plant. It suggests that $P$. mediterranea EDOX may be a true endophyte and play a beneficial role in tomato plants. This phenomenon is reasonable since the different behavior of same species can be explained by rather subtle differences (e.g., the expression of genes involved in plant defense reactions; Sheibani-Tezerji et al., 2015) and the influences from the host and/or the environmental conditions (Brader et al., 2017). For instance, P. syringae is a well-known pathogen worldwide, while $P$. syringae 260-02 was shown to promote plant growth and exert biocontrol of $P$. syringae pv. tomato DC3000, Botrytis cinerea, and Cymbidium Ringspot (Passera et al., 2019). The biocontrol ability and its mechanisms of $P$. mediterranea EDOX need to be further research.

Genome mining has become a powerful tool for the discovery of microbial natural products and understanding the activity 
profiles of bacteria. One of the advantages of this approach is that it unveils the full biosynthetic capacity of a microorganism (Jahanshah et al., 2019). The ever-increasing availability of genome sequencing data and the bioinformatic annotation of biosynthetic gene clusters (BGCs) facilitates the discovery of novel natural products. The inspection of a new Pseudomonas genome allowed us to predict the peptide sequence of multiple new variants and to identify potential producers of CLPs.

The BGC for biosynthesis of medipeptins in Pseudomonas sp. EDOX is quite similar to that of some known CLPs BGCs in Pseudomonas strains, including corpeptin BGC and nunapeptin BGC (Michelsen et al., 2015; Strano et al., 2015), but the structure and function of the potential CLPs produced by strain EDOX have not yet been investigated. The biosynthesis of medipeptin A and $\mathrm{B}$ is catalyzed by three NRPS genes (mepA, $m e p B$, and $m e p C$ ) in a collinear manner (Figure 3). By combining genome mining and LC-MS/MS analysis, we have determined the molecular structure of medipeptin $\mathrm{A}$ and medipeptin B. Medipeptins were produced as a family of cyclic lipopeptides of 22 amino acid residues with molecular masses $2082.20[\mathrm{M}+\mathrm{H}]^{+}$(medipeptin $\mathrm{A}$ ) and $2051.18 \quad[\mathrm{M}+\mathrm{H}]^{+}$ (medipeptin B; Figure 1).

Even though there are some reports showing the antimicrobial and/or antifungal activity of similar CLPs (corpeptin, nunapeptin, etc.), the antimicrobial mode of action of them is still not clear. To this end, we investigated the antimicrobial mechanisms of medipeptin A. In this study, we show that the newly discovered medipeptin A exerts its potent antimicrobial activity against Gram-positive pathogens via binding to both LTA and lipid II and probably by subsequently forming pores in membranes. LTA is a crucial constituent of Gram-positive cell envelopes, consisting of a poly (GroP) backbone linked to a glycolipid membrane anchor (Edgar et al., 2019). LTA, which is anchored to the cell envelope, could control autolysin activity. The interaction of CLPs with LTAs can result in loss of regulation of autolysins, which then causes autolysis by hydrolyzing peptidoglycan chains and peptide bridges of murein (Bierbaum and Sahl, 1985). In addition, the interaction between LTA and CLPs is believed to facilitate penetration of CLPs through the thick peptidoglycan layer, allowing the CLPs to reach and act on the cytoplasmic membrane (Yasir et al., 2019). In our study (Figure 4C), the added LTAs affect the activity of medipeptin A against $S$. aureus, which suggests that medipeptin A binds to LTA. Since lipid II is the bactoprenol-bound precursor of the bacterial cell wall, binding to lipid II could block the

\section{REFERENCES}

Alippi, A. M., and López, A. C. (2010). First report of Pseudomonas mediterranea causing tomato pith necrosis in Argentina. Plant Pathol. 59:1163. doi: 10.1111/j. 1365-3059.2010.02291.x

Andrews, S. (2010). FastQC: A Quality Control Tool for High Throughput Sequence Data. Available at: http://www.bioinformatics.babraham.ac.uk/ projects/fastqc/ (Accessed December 7, 2020).

Baars, O., Zhang, X., Gibson, M. I., Stone, A. T., Morel, F. M., and Seyedsayamdost, M. R. (2018). Crochelins: siderophores with an unprecedented iron-chelating moiety from the nitrogen-fixing bacterium Azotobacter chroococcum. Angew. Chem. 130, 545-550. doi: 10.1002/ange.201709720 incorporation of lipid II into peptidoglycan, resulting in slow cell lysis and/or enhances the stability of pore formation, which increases the activity of the peptide (Bauer and Dicks, 2005). Based on the lipid II binding assay and the fact that the antimicrobial activity of medipeptin A decreased after treatment of the cells with lipid II (Figure 4D), we suggest that medipeptin A can also bind to lipid II to exert its activity against $S$. aureus. In addition, we observed that cells of $S$. aureus could be stained red after treated with medipeptin A, indicating that medipeptin A shows pore-forming activity in biological membranes of $S$. aureus (Figure 4B).

To conclude, we isolated $P$. mediterranea EDOX from tomato endosphere. One BGC encoding the novel medipeptin biosynthesis cluster was identified from the genome sequence of EDOX. The purified medipeptin A has bactericidal activity against Gram-positive pathogens, but a bacteriostatic activity toward Gram-negative pathogens. We also show that medipeptin A combats Gram-positive pathogens through binding both to LTA and lipid II, as well as by forming pores in membranes. This study provides novel insights into the antimicrobial mode of action of medipeptin $\mathrm{A}$, which broadens the array of candidates for drug development and biocontrol agents.

\section{DATA AVAILABILITY STATEMENT}

The original contributions presented in the study are included in the article/supplementary material, further inquiries can be directed to the corresponding author.

\section{AUTHOR CONTRIBUTIONS}

LZ and OK conceived the study, designed the experiments, and corrected the manuscript. AJ and YY assembled the draft genome. LZ performed the experiments and wrote the draft manuscript. All authors contributed to the article and approved the submitted version.

\section{FUNDING}

LZ was financially supported by the China Scholarship Council (201606910037). YY was financially supported by the China Scholarship Council (201904910477).
Bankevich, A., Nurk, S., Antipov, D., Gurevich, A. A., Dvorkin, M., Kulikov, A. S., et al. (2012). SPAdes: a new genome assembly algorithm and its applications to single-cell sequencing. J. Comput. Biol. 19, 455-477. doi: 10.1089/cmb.2012.0021 Bauer, R., and Dicks, L. M. T. (2005). Mode of action of lipid II-targeting lantibiotics. Int. J. Food Microbiol. 101, 201-216. doi: 10.1016/j.ijfoodmicro.2004.11.007

Bierbaum, G., and Sahl, H.-G. (1985). Induction of autolysis of staphylococci by the basic peptide antibiotics Pep 5 and nisin and their influence on the activity of autolytic enzymes. Arch. Microbiol. 141, 249-254. doi: 10.1007/ BF00408067

Blin, K., Shaw, S., Steinke, K., Villebro, R., Ziemert, N., Lee, S. Y., et al. (2019). antiSMASH 5.0: updates to the secondary metabolite genome mining pipeline. Nucleic Acids Res. 47, W81-W87. doi: 10.1093/nar/gkz310 
Bolger, A. M., Lohse, M., and Usadel, B. (2014). Trimmomatic: a flexible trimmer for Illumina sequence data. Bioinformatics 30, 2114-2120. doi: 10.1093/ bioinformatics/btu170

Bosi, E., Donati, B., Galardini, M., Brunetti, S., Sagot, M. F., Lio, P., et al. (2015). MeDuSa: a multi-draft based scaffolder. Bioinformatics 31, 2443-2451. doi: 10.1093/bioinformatics/btv171

Brader, G., Compant, S., Vescio, K., Mitter, B., Trognitz, F., Ma, L.-J., et al. (2017). Ecology and genomic insights into plant-pathogenic and plantnonpathogenic endophytes. Annu. Rev. Phytopathol. 55, 61-83. doi: 10.1146/ annurev-phyto-080516-035641

D'aes, J., De Maeyer, K., Pauwelyn, E., and Höfte, M. (2010). Biosurfactants in plant-Pseudomonas interactions and their importance to biocontrol. Environ. Microbiol. Rep. 2, 359-372. doi: 10.1111/j.1758-2229.2009.00104.x

Edgar, R. J., Van Hensbergen, V. P., Ruda, A., Turner, A. G., Deng, P., Le Breton, Y., et al. (2019). Discovery of glycerol phosphate modification on streptococcal rhamnose polysaccharides. Nat. Chem. Biol. 15, 463-471. doi: 10.1038/s41589-019-0251-4

Emanuele, M. C., Scaloni, A., Lavermicocca, P., Jacobellis, N. S., Camoni, L., Di Giorgio, D., et al. (1998). Corceptins, new bioactive lipodepsipeptides from cultures of Pseudomonas corrugata. FEBS Lett. 433, 317-320. doi: 10.1016/S0014-5793(98)00933-8

Geudens, N., and Martins, J. C. (2018). Cyclic Lipodepsipeptides From Pseudomonas spp. - Biological Swiss-Army Knives. Front. Microbiol. 9:1867. doi: 10.3389/ fmicb.2018.01867

Götze, S., Herbst-Irmer, R., Klapper, M., GöRls, H., Schneider, K. R., Barnett, R., et al. (2017). Structure, biosynthesis, and biological activity of the cyclic lipopeptide anikasin. ACS Chem. Biol. 12, 2498-2502. doi: 10.1021/ acschembio.7b00589

Gotze, S., and Stallforth, P. (2020). Structure, properties, and biological functions of nonribosomal lipopeptides from pseudomonads. Nat. Prod. Rep. 37, 29-54. doi: 10.1039/C9NP00022D

Gross, H., and Loper, J. E. (2009). Genomics of secondary metabolite production by Pseudomonas spp. Nat. Prod. Rep. 26, 1408-1446. doi: 10.1039/b817075b

Hennessy, R. C., Phippen, C. B., Nielsen, K. F., Olsson, S., and Stougaard, P. (2017). Biosynthesis of the antimicrobial cyclic lipopeptides nunamycin and nunapeptin by Pseudomonas fluorescens strain In5 is regulated by the LuxRtype transcriptional regulator NunF. Microbiology 6:e0516. doi: 10.1002/ mbo3.516

Hindler, J.A., and Richter, S.S. (2016). Methods for Antimicrobial Dilution and Disk Susceptibility Testing of Infrequently Isolated or Fastidious Bacteria: M45. Wayne, PA: Clinical and Laboratory Standards Institute.

Jahanshah, G., Yan, Q., Gerhardt, H., Pataj, Z., Lammerhofer, M., Pianet, I., et al. (2019). Discovery of the cyclic lipopeptide gacamide A by genome mining and repair of the defective GacA regulator in Pseudomonas fluorescens Pf0-1. J. Nat. Prod. 82, 301-308. doi: 10.1021/acs.jnatprod.8b00747

Jenul, C., Sieber, S., Daeppen, C., Mathew, A., Lardi, M., Pessi, G., et al. (2018). Biosynthesis of fragin is controlled by a novel quorum sensing signal. Nat. Commun. 9:1297. doi: 10.1038/s41467-018-03690-2

Ling, L. L., Schneider, T., Peoples, A. J., Spoering, A. L., Engels, I., Conlon, B. P., et al. (2015). A new antibiotic kills pathogens without detectable resistance. Nature 517, 455-459. doi: 10.1038/nature14098

Loper, J. E., Hassan, K. A., Mavrodi, D. V., Davis, E. W. 2nd, Lim, C. K., Shaffer, B. T., et al. (2012). Comparative genomics of plant-associated Pseudomonas spp.: insights into diversity and inheritance of traits involved in multitrophic interactions. PLoS Genet. 8:e1002784. doi: 10.1371/journal.pgen.1002784

Masschelein, J., Jenner, M., and Challis, G. L. (2017). Antibiotics from Gramnegative bacteria: a comprehensive overview and selected biosynthetic highlights. Nat. Prod. Rep. 34, 712-783. doi: 10.1039/C7NP00010C

Meier-Kolthoff, J. P., and Goker, M. (2019). TYGS is an automated highthroughput platform for state-of-the-art genome-based taxonomy. Nat. Commun. 10:2182. doi: 10.1038/s41467-019-10210-3

Michelsen, C. F., Watrous, J., Glaring, M. A., Kersten, R., Koyama, N., Dorrestein, P. C., et al. (2015). Nonribosomal peptides, key biocontrol components for Pseudomonas fluorescens In5, isolated from a Greenlandic suppressive soil. mBio 6:e00079. doi: 10.1128/mBio.00079-15

Mochizuki, S., Hiratsu, K., Suwa, M., Ishii, T., Sugino, F., Yamada, K., et al. (2003). The large linear plasmid pSLA2-L of Streptomyces rochei has an unusually condensed gene organization for secondary metabolism. Mol. Microbiol. 48, 1501-1510. doi: 10.1046/j.1365-2958.2003.03523.x
Muller, A., Wenzel, M., Strahl, H., Grein, F., Saaki, T. N. V., Kohl, B., et al. (2016). Daptomycin inhibits cell envelope synthesis by interfering with fluid membrane microdomains. Proc. Natl. Acad. Sci. U. S. A. 113, E7077-E7086. doi: $10.1073 /$ pnas.1611173113

Passera, A., Compant, S., Casati, P., Maturo, M. G., Battelli, G., Quaglino, F., et al. (2019). Not just a pathogen? Description of a plant-beneficial Pseudomonas syringae strain. Front. Microbiol. 10:1409. doi: 10.3389/fmicb.2019.01409

Raaijmakers, J. M., De Bruijn, I., and De Kock, M. J. (2006). Cyclic lipopeptide production by plant-associated Pseudomonas spp.: diversity, activity, biosynthesis, and regulation. Mol. Plant-Microbe Interact. 19, 699-710. doi: 10.1094/MPMI-19-0699

Reybroeck, W., De Vleeschouwer, M., Marchand, S., Sinnaeve, D., Heylen, K., De Block, J., et al. (2014). Cyclic lipodepsipeptides produced by Pseudomonas spp. naturally present in raw milk induce inhibitory effects on microbiological inhibitor assays for antibiotic residue screening. PLoS One 9:e98266. doi: 10.1371/journal.pone.0098266

Richter, M., Rossello-Mora, R., Oliver Glockner, F., and Peplies, J. (2016). JSpeciesWS: a web server for prokaryotic species circumscription based on pairwise genome comparison. Bioinformatics 32, 929-931. doi: 10.1093/ bioinformatics/btv681

Scholz-Schroeder, B. K., Hutchison, M. L., Grgurina, I., and Gross, D. C. (2001). The contribution of syringopeptin and syringomycin to virulence of Pseudomonas syringae pv. Syringae strain B301D on the basis of sypA and syrB1 biosynthesis mutant analysis. Mol. Plant-Microbe Interact. 14, 336-348. doi: 10.1094/MPMI.2001.14.3.336

Scholz-Schroeder, B. K., Soule, J. D., and Gross, D. C. (2003). The sypA, sypB, and sypC synthetase genes encode twenty-two modules involved in the nonribosomal peptide synthesis of syringopeptin by Pseudomonas syringae pv. Syringae B301D. Mol. Plant-Microbe Interact. 16, 271-280. doi: 10.1094/ MPMI.2003.16.4.271

Schwarzer, D., Finking, R., and Marahiel, M. A. (2003). Nonribosomal peptides: from genes to products. Nat. Prod. Rep. 20, 275-287. doi: 10.1039/b111145k

Sheibani-Tezerji, R., Naveed, M., Jehl, M.-A., Sessitsch, A., Rattei, T., and Mitter, B. (2015). The genomes of closely related Pantoea ananatis maize seed endophytes having different effects on the host plant differ in secretion system genes and mobile genetic elements. Front. Microbiol. 6:440. doi: 10.3389/fmicb. 2015.00440

Strano, C. P., Bella, P., Licciardello, G., Fiore, A., Lo Piero, A. R., Fogliano, V., et al. (2015). Pseudomonas corrugata crpCDE is part of the cyclic lipopeptide corpeptin biosynthetic gene cluster and is involved in bacterial virulence in tomato and in hypersensitive response in Nicotiana benthamiana. Mol. Plant Pathol. 16, 495-506. doi: 10.1111/mpp.12207

Vallet-Gely, I., Novikov, A., Augusto, L., Liehl, P., Bolbach, G., Péchy-Tarr, M., et al. (2010). Association of hemolytic activity of Pseudomonas entomophila, a versatile soil bacterium, with cyclic lipopeptide production. Appl. Environ. Microbiol. 76, 910-921. doi: 10.1128/AEM.02112-09

Van Der Voort, M., Meijer, H. J., Schmidt, Y., Watrous, J., Dekkers, E., Mendes, R., et al. (2015). Genome mining and metabolic profiling of the rhizosphere bacterium Pseudomonas sp. SH-C52 for antimicrobial compounds. Front. Microbiol. 6:693. doi: 10.3389/fmicb.2015.00693

Van Heel, A. J., De Jong, A., Song, C., Viel, J. H., Kok, J., and Kuipers, O. P. (2018). BAGEL4: a user-friendly web server to thoroughly mine RiPPs and bacteriocins. Nucleic Acids Res. 46, W278-W281. doi: 10.1093/nar/gky383

Vater, J., Herfort, S., Doellinger, J., Weydmann, M., Borriss, R., and Lasch, P. (2018). Genome Mining of the lipopeptide biosynthesis of Paenibacillus polymyxa $\mathrm{E} 681$ in combination with mass spectrometry: discovery of the lipoheptapeptide paenilipoheptin. ChemBioChem 19, 744-753. doi: 10.1002/ cbic. 201700615

Weissman, K. J. (2015). The structural biology of biosynthetic megaenzymes. Nat. Chem. Biol. 11, 660-670. doi: 10.1038/nchembio.1883

Wiegand, I., Hilpert, K., and Hancock, R. E. (2008). Agar and broth dilution methods to determine the minimal inhibitory concentration (MIC) of antimicrobial substances. Nat. Protoc. 3, 163-175. doi: 10.1038/nprot.2007.521

Yang, X., Huang, E., and Yousef, A. E. (2017). Brevibacillin, a cationic lipopeptide that binds to lipoteichoic acid and subsequently disrupts cytoplasmic membrane of Staphylococcus aureus. Microbiol. Res. 195, 18-23. doi: 10.1016/j. micres.2016.11.002

Yasir, M., Dutta, D., and Willcox, M. D. (2019). Mode of action of the antimicrobial peptide Mel4 is independent of Staphylococcus aureus cell 
membrane permeability. PLoS One 14:e0215703. doi: 10.1371/journal. pone. 0215703

Zhao, H., Liu, Y. P., and Zhang, L. Q. (2019). In silico and genetic analyses of cyclic lipopeptide synthetic gene clusters in Pseudomonas sp. 11K1. Front. Microbiol. 10:544. doi: 10.3389/fmicb.2019.00544

Zhou, L., Song, C., Li, Z., and Kuipers, O. P. (2021). Antimicrobial activity screening of rhizosphere soil bacteria from tomato and genome-based analysis of their antimicrobial biosynthetic potential. BMC Genomics 22:29. doi: $10.1186 /$ s12864-020-07346-8

Conflict of Interest: The authors declare that the research was conducted in the absence of any commercial or financial relationships that could be construed as a potential conflict of interest.
Publisher's Note: All claims expressed in this article are solely those of the authors and do not necessarily represent those of their affiliated organizations, or those of the publisher, the editors and the reviewers. Any product that may be evaluated in this article, or claim that may be made by its manufacturer, is not guaranteed or endorsed by the publisher.

Copyright (c) 2021 Zhou, de Jong, Yi and Kuipers. This is an open-access article distributed under the terms of the Creative Commons Attribution License (CC BY). The use, distribution or reproduction in other forums is permitted, provided the original author(s) and the copyright owner(s) are credited and that the original publication in this journal is cited, in accordance with accepted academic practice. No use, distribution or reproduction is permitted which does not comply with these terms. 